\title{
ANTROPOGÊNESE DAS DOENÇAS ORGÂNICAS: UMA NOVA VISÃO EM PSICOSSOMÁTICA
}

Guilherme de Andrade Salgado

Pontifícia Universidade Católica do Rio de Janeiro

Carlos Augusto Peixoto Junior

Pontifícia Universidade Católica do Rio de Janeiro
Recebido em: 27/04/2020

$1^{\text {a }}$ revisão em: $11 / 08 / 2020$

$2^{a}$ revisão em: 16/02/2021

Aceito em: 12/05/2021

\section{RESUMO}

O debate sobre a relação mente-corpo, um dos maiores problemas filosóficos existentes, perpassa outras áreas do conhecimento. Do ponto de vista da prática psicoterápica, o atendimento a pacientes com doenças orgânicas contribuiu para o surgimento do campo da psicossomática. Inicialmente, esse artigo visa apresentar os principais conceitos das Escolas de Psicossomática de Chicago e Paris, as mais relevantes no Ocidente. Como resposta a essas visões, consideradas reducionistas e exageradamente intrapsíquicas, serão apresentados estudos sobre o vínculo humano. A partir de tal descrição emergirá uma proposta de compreensão teórica do fenômeno psicossomático tomando como matriz as considerações conceituais de Danilo Perestrello e Abram Eksterman, psicanalistas brasileiros, cujo ponto nodal é o entendimento da doença somática em sua dimensão antropogênica. As ideias contidas nesse pensamento serão a base para a noção de adoecimento somático enquanto resposta às dificuldades presentes no campo relacional.

Palavras-chave: psicossomática; psicanálise; relação mente-corpo; adoecimento físico. 


\section{ANTHROPOGENESIS OF ORGANIC DISEASES: A NEW VISION IN PSYCHOSOMATICS}

\section{ABSTRACT}

The debate about the mind-body relationship, one of the greatest philosophical problems, permeates other areas of knowledge. From the point of view of psychotherapeutic practice, care for patients with organic diseases contributed to the emergence of the psychosomatic field. Initially, this article aims to present the main concepts of Chicago and Paris Psychosomatic Schools, the most relevant in the West. In response to these views, considered reductionist and exaggeratedly intrapsychic, studies on the human bond will be presented. From this description, a theoretical proposal to understand the psychosomatic phenomenon will emerge, taking as matrix the conceptual considerations of Danilo Perestrello and Abram Eksterman, Brazilian psychoanalysts, whose nodal point is the understanding of somatic disease in its anthropogenic dimension. The ideas contained in this thought will be the basis for the notion of somatic illness as an answer to the relational field difficulties.

Keywords: psychosomatics; psychoanalysis; mind-body relationship; organic illness. 


\section{ANTROPOGÉNESIS DE LAS ENFERMEDADES ORGÁNICAS: UNA NUEVA VISIÓN EN PSICOSOMÁTICA}

\section{RESUMEN}

La relación mente-cuerpo, uno de los mayores problemas filosóficos existentes, impregna otras áreas del conocimiento. Desde la práctica psicoterapéutica, el cuidado de los pacientes con enfermedades orgánicas ha contribuido a la aparición del campo psicosomático. Inicialmente, este artículo tiene como objetivo presentar los principales conceptos de las Escuelas de Psicosomática de Chicago y París, las más relevantes en Occidente. En respuesta a estos puntos de vista, reduccionistas y exageradamente intrapsíquicos, se presentarán estudios sobre el vínculo humano. De esta descripción surgirá una propuesta teórica para comprender el fenómeno psicosomático tomando como matriz las consideraciones conceptuales de Danilo Perestrello y Abram Eksterman, psicoanalistas brasileños, cuyo punto nodal es la comprensión de la enfermedad somática en su dimensión antropogénica. Las ideas contenidas en este pensamiento serán la base de la noción de enfermedad somática como respuesta a las dificultades del campo relacional.

Palabras clave: psicosomática; psicoanálisis; relación mente-cuerpo; enfermedad somática. 


\section{INTRODUÇÃO}

O adoecimento, tanto mental quanto orgânico, é objeto de investigação desde os primórdios da civilização humana. Ainda hoje, a questão da relação mente-corpo é entendida como um dos maiores problemas para a filosofia. As posições possíveis variam entre dois grandes espectros: o dualismo e o monismo. Por definição, o primeiro diz respeito à compreensão da mente e do corpo enquanto duas substâncias diferentes; o segundo, por sua vez, recorre à existência de apenas uma substância, em geral material.

Uma corrente da filosofia da mente parece estar em harmonia com a visão psicanalítica, sustentação teórica desse trabalho, sendo capaz de dialogar com sua forma de conceber a gênese mental, sua desorganização e os distúrbios orgânicos (Cheniaux \& Lyra, 2014). O monismo não redutivo - ou emergentismo - parte da ideia de que o surgimento dos fenômenos mentais não é redutivo ao funcionamento bioquímico do cérebro e suas sinapses e, por outro lado, também não considera tais fenômenos como de outra ordem em termos substanciais. A mente emerge do cérebro, afinal sem cérebro não há aquilo que chamamos de vida humana, mas não é redutível a ele (Maslin, 2009).

Tomando como base essa premissa teórica, não só a filosofia deve se ocupar do estudo da relação mente-corpo: posicionar-se dentro desse debate é importante para diversos profissionais, dentre outros, os de psicologia clínica - aqui incluídas todas as suas filiações teóricas - de modo a balizarem suas intervenções junto a pacientes com patologias somáticas.

Para além da concepção predominantemente intrapsíquica postulada pela metapsicologia freudiana, o artigo buscará no entendimento intersubjetivo do desenvolvimento humano uma possibilidade mais ampla de compreensão das afecções orgânicas. Tendo como sustentação básica o fato de o Homem existir enquanto ser de relação, será apresentada uma abordagem que concebe a mente a partir da relação com outros objetos e o ambiente desde os primórdios do desenvolvimento individual, reconhecendo que distúrbios nos vínculos podem estar em correlação com doenças físicas.

Assim, sob a égide de uma visão monista não redutiva, a proposta é apresentar uma ideia que permita pensar o adoecimento orgânico como um dos resultados de impactos e dificuldades nas relações humanas. O pensamento se guiará tendo como premissa o fato de que, embora a mente emerja de processos físicos, é através das relações intersubjetivas que acompanham o indivíduo humano desde seu nascimento - ou antes - que ela se desenvolve. Vínculos mal erguidos, rupturas, (ameaças de) perdas e mudanças bruscas nas relações, etc, podem ser disparadores para a desorganização orgânica mediante alteração nas funções fisiológicas. 


\section{O PROBLEMA MENTE-CORPO NA MEDICINA}

Foi com Hipócrates (460 a.C - 377 a.C) que a psiquê ganhou o status de reguladora do soma, passando a figurar como uma grande parte orgânica do ser (Volich, 2010). Surgiu, assim, a "medicina" voltada ao ser humano, ao doente como um todo. Para compreender o adoecimento, Hipócrates dava extrema importância à observação e ao contato direto com o paciente e sua família, além de procurar compreender o ambiente social no qual vivia. Havia, para ele, um ineditismo em cada história contada por aqueles que o procuravam. Dessa maneira, estava presente a noção de que o entendimento do adoecer humano passaria, obrigatoriamente, pela investigação e reconhecimento das faces sócio-históricas do ser humano. O "Pai da Medicina", diretamente da ilha grega de Cós, afirmava que:

A doença seria um desequilíbrio nos humores corporais em consequência das disposições naturais do paciente, das influências do meio natural e das ações atuais do paciente. Sendo assim, o objetivo da terapêutica era restaurar a unidade do todo orgânico ameaçado pela doença (...) considerando também a natureza do doente (Volich, 2010, p. 34).

O pensamento hipocrático dominou a ideologia médica grega durante muitas décadas. Muito antes dos debates do campo moderno conhecido como filosofia da mente, e evidentemente perpassado pelas concepções espirituais de sua época, Hipócrates e seus seguidores já manifestavam a compreensão de uma integridade psicossomática do indivíduo.

Os séculos subsequentes, com o surgimento do Império Romano a partir da anexação cultural do ideário grego, foram de grande florescimento nos estudos do funcionamento corporal e nas formas de intervenção nas desorganizações da psiquê. Porém, com o passar do tempo e a entrada na Idade Média instituiu-se o domínio da Igreja Católica e a decadência do caráter investigativo dos fenômenos naturais. Dessa maneira, as proposições médicas do período grego, sobretudo as hipocráticas, foram soterradas. Houve uma divisão das responsabilidades: ficaram a cargo da Igreja as explicações sobre os fenômenos mentais; com os médicos, a autoridade no que dizia respeito às investigações das doenças estritamente corporais e seus tratamentos (Volich, 2010). Ou seja, uma cisão vigorosa entre corpo e espírito se instaura nesse momento.

Tempos depois, com o Renascimento, foi retomada "uma orientação humanística que apagou a fogueira da Inquisição" (Mello Filho, 1979, p. 15). O desenvolvimento das ciências, artes e filosofia voltou a ocorrer, e a relativa liberdade de pensamento, onde o ser humano tornou-se o centro criativo e investigador dos fenômenos naturais, permitiu o surgimento de um novo olhar sobre o Homem e sobre as manifestações inerentes à sua existência. 
Adiante, a partir de sua herança renascentista, o método científico e a concepção dualista de René Descartes (1596 - 1650) tiveram seu apogeu. Assim, a doença física deveria ser sempre investigada dentro do campo das ciências naturais. A medicina passou a ser contemplada como uma dessas ciências, cujo método deveria respeitar os procedimentos científicos estabelecidos: partindo da premissa de que o corpo humano respeitaria um funcionamento equivalente ao de uma máquina, seria possível o entendimento completo dos sintomas orgânicos apresentados. Ou seja, a doença passa a ser concebida como um fator externo ao Homem. Para além de outras consequências do racionalismo cartesiano, esse efeito é de suma importância aqui: ao cindir corpo e mente, substância extensa e substância pensante, Descartes fundamentou filosoficamente uma visão que pressupunha a impossibilidade de um indivíduo enquanto entidade psicossomática. Em Volich (2010) encontramos a ideia de que "essa visão (...) acabou imprimindo uma tendência a priorizar a clareza e a distinção do corpo e de suas funções, valorizando seu substrato material em detrimento da subjetividade" (p. 49).

Com o lluminismo houve uma mudança que se faria presente na prática médica a partir de então. O psiquiatra alemão Johann Christian Heinroth (1773 - 1843) cunhou, em 1818, o termo "psicossomática" ao descrever a influência das paixões sobre doenças como a tuberculose, epilepsia e o câncer. Nesse trabalho, Heinroth ressaltou a importância da conjugação entre os espaços físico e anímico do adoecer (Volich, 2010). De acordo com Tenenbaum (2013), o autor alemão buscava realçar a importância dos problemas espirituais - hoje denominados mentais - no adoecimento orgânico e chamar a atenção para a interação entre as duas esferas do existir: a existencial e a biológica. É nesse contexto que, poucas décadas depois, nascerá a psicanálise.

Sigmund Freud, ao desenvolver o método psicanalítico, o fez buscando o ideal de neutralidade e de objetividade científica do positivismo da época (Lessem, 2005). Os estudos sobre a histeria o levaram a estabelecer relações entre psiquismo e soma, e a propor formas de se encarar a dinâmica entre os dois. O corpo físico poderia ser concebido enquanto cenário de manifestações do material recalcado que retorna, uma espécie de local onde se encenariam conflitos inconscientes (Freud, 1895/1974). Essa era a questão essencial da abordagem psicodinâmica dos sintomas histéricos: o corpo poderia ser concebido enquanto espaço de manifestações do extravasamento da quantidade pulsional outrora ligada a representações mentais. Porém, é necessário diferenciar os acometimentos de ordem funcional em determinadas áreas do corpo, tal como acontece na histeria, de modificações estruturais de fato, que são justamente as questões sobre as quais o campo da psicossomática passou a se debruçar e que nos interessam, do ponto de vista teórico, nesse artigo.

Assim, seguindo o rastro do fundador, alguns psicanalistas enveredaram pelos campos que ficaram conhecidos como "medicina psicossomática" e "psicossomática psicanalítica", que ganharam extrema importância na segunda 
metade do século XX. Na Europa e nas Américas, diferentes Escolas/Institutos se consolidaram ao tentar explicar e intervir sobre as doenças físicas tendo como base a teoria psicanalítica. A partir dos estudos desenvolvidos nesses locais, enormes avanços na compreensão do adoecimento orgânico e correlações com o funcionamento psíquico foram possíveis.

\section{PSICOSSOMÁTICA E O NASCIMENTO DA PSICANÁLISE}

É a partir do espanto de Freud com as apresentações de Charcot e a utilização da hipnose como forma de cessar os sintomas de conversão histérica, na qual a sintomatologia orgânica se dava em termos funcionais e não estruturais, que surge o conceito de inconsciente dinâmico (Jones, 1957). Mesmo tendo iniciado suas pesquisas influenciado pela neurofisiologia, Freud contribuiu diretamente para o desenvolvimento dos estudos sobre a psicodinâmica, uma forma de conceber o funcionamento mental inteiramente diferente daquela estabelecida pela psiquiatria clássica. Diferente porque a mente, até então uma área de interesse da psicologia geral e cujos distúrbios eram tratados com base na psiquiatria e na neurologia, passou a ser entendida como passível de organização e desorganização inerentes às questões afetivas, relacionais e sócio-históricas do ser humano (Luchina, 1971).

Uma das principais descobertas, e que precipitou o surgimento da psicanálise enquanto campo do saber independente, foi justamente o mecanismo da conversão histérica, processo basal nessa enfermidade onde o afeto desligado de uma representação, em virtude de incompatibilidade com o sistema préconsciente-consciente, busca descarga através da inervação somática (Freud, 1895/1974). Assim, podemos inferir que o nascimento da psicanálise tem em seu bojo uma inquietação de seu fundador com o problema da relação mente-corpo. Sobre isso, Volich (2007) afirma que:

De ponta a ponta - nas descobertas sobre os sonhos e sobre a sexualidade, nos modelos do aparelho psíquico e das pulsões, sua obra (de Freud) apresenta uma reflexão sobre as relações entre o psíquico e o somático. O modelo etiológico da histeria e da neurose atual se constituíram como as primeiras referências da psicanálise para pensar a participação dos fatores psíquicos nas doenças orgânicas (p. 10).

Com suas descobertas sobre a dinâmica mental e a etiologia das neuroses, Freud abriu um leque de possibilidades de estudo e tratamento para os pacientes diante do adoecimento da mente e do corpo. Assim, preocupados em tentar explicar a gênese do adoecimento físico, diversos psicanalistas foram buscar na mente suas possíveis respostas (Alexander, 1989; Marty, 1993; Tenenbaum, 2017). Para Eksterman (2010): 
A psicossomática configura-se como o estudo empírico das relações mente-corpo e formulação das bases teóricas para a compreensão sistêmica das doenças e intervenções transdisciplinares. É o produto da tentativa da psicanálise de intervir teórica e clinicamente na patologia somática (p. 48).

George Engel (1962) formula a ideia de um desenvolvimento do que chamou de "Medicina Psicossomática" em momentos distintos. O primeiro deles surge a partir da experiência freudiana e seus posteriores ensinamentos a respeito da histeria, cujo mecanismo de conversão gerou grande expectativa em toda a comunidade médica da época. Haveria, nos sintomas somáticos funcionais de tal enfermidade, referências à relação mente-corpo tão estranhamente entendida até então. O segundo momento sucedeu-se a partir do desenvolvimento de explicações para alguns tipos de doenças físicas tendo como base conceitos retirados da psicanálise. É esse segundo momento que será mais bem detalhado nesse trabalho.

Lipowski (1977) concorda com Engel e apresenta uma divisão da história da Psicossomática em 3 fases. A primeira compreende o período anterior a 1920, influenciada pelo surgimento da psicanálise, mas com o entendimento da relação mente-corpo ainda muito aderida ao pensamento estritamente filosófico, metafísico, por assim dizer. A segunda estaria circunscrita entre os anos 20 e o final da década de 50, com a tentativa de intervenção psicodinâmica dos sintomas físicos de diferentes enfermidades com lesões e prejuízos orgânicos comprovados. E a terceira fase, a partir dos anos 60 , quando o campo psicossomático passou a ser fortemente influenciado pelos estudos fisiológicos e neurocientíficos. Vejamos a seguir, de maneira descritiva e crítica, as ideias contidas nos dois principais polos de pesquisa e ensino do campo psicossomático no Ocidente.

\section{OS PRINCIPAIS INSTITUTOS DE PSICOSSOMÁTICA OCIDENTAIS: CHICAGO E PARIS}

Os psicanalistas integrantes dos principais centros de pesquisa e atuação em psicossomática do Ocidente debruçaram-se sobre diferentes postulados da Psicanálise para compreender e intervir sobre pacientes que sofriam do corpo. Abandonando o modelo clássico da histeria - ou seja, o mecanismo de conversão - os profissionais desses centros buscaram, cada um à sua maneira, outros caminhos: incluíram aspectos da personalidade, conhecimentos psicofisiológicos e usaram o mecanismo básico das neuroses atuais para compreender e intervir sobre os ditos pacientes psicossomáticos (Tenenbaum, 2017). Apesar de reconhecer a grande importância de Felix Deutsch, em Boston, com sua ideia de anamnese associativa (Volich, 2010) e Flanders Dunbar, em Nova lorque, com os estudos sobre personalidade e influência das mesmas nos tipos de doença (Tenenbaum, 2017), aqui daremos ênfase ao trabalho desenvolvido em Chicago no que tange especificamente às ideias psicossomáticas desenvolvidas nos Estados Unidos. 
Franz Alexander, médico e psicanalista nascido na Hungria, analisando de Ferenczi, migrou para os Estados Unidos em 1929. Lá, preocupado em entender o aparecimento das afecções somáticas funcionais em decorrência de conflitos psicológicos inconscientes, ajudou a criar o Instituto Psicossomático de Chicago. Segundo Alexander (1989), em quase todos os problemas físicos crônicos os fatores emocionais teriam um papel importante, e caberia ao campo psicossomático estudar o funcionamento do aparelho psíquico humano durante o aparecimento de uma doença biológica, intervindo terapeuticamente.

O autor formulou duas categorias de doenças: os estados conversivos e as neuroses vegetativas. No que diz respeito aos estados conversivos, como o nome evidencia, Alexander postulou que esses quadros comportavam um simbolismo referente aos sintomas, isto é, seriam a expressão do recalque de conteúdos insuportáveis para o ego - ocorrências de conversão histérica, por exemplo. Para o autor, esses estados têm como finalidade o alívio de tensões psicológicas em manifestações corporais.

O grupo de Chicago também tentou descrever de que maneira se dava o surgimento das doenças físicas com prejuízos estruturais - as neuroses vegetativas -, mediadas pelo sistema nervoso autônomo e cujas alterações aconteceriam em glândulas, músculos lisos e vasos. A partir disso, Alexander e seus colaboradores criou a teoria da "Constelação Psicodinâmica Específica". De acordo com essa teoria, o aparecimento de uma doença física seria função do somatório entre a vulnerabilidade de algum órgão/sistema e a constelação psicodinâmica do paciente, sua forma específica de funcionamento psíquico (Alexander, 1989).

Ou seja, haveria tipos de funcionamento psíquico característicos e mais propensos ao desenvolvimento de certas doenças orgânicas. Em outras palavras, determinados aspectos psicodinâmicos, próprios de cada indivíduo, poderiam estar no cerne de algumas afecções somáticas. Cada um desses funcionamentos psicodinâmicos específicos estaria correlacionado a uma síndrome característica. Nesse quadro se encontram as sete doenças que ficaram popularmente conhecidas como "psicossomáticas" e que foram alvo de extenso estudo do grupo de Chicago. São elas: artrite, asma, colite ulcerativa, hipertensão, neurodermite, úlcera e doença de Graves (Alexander, 1989).

Essa visão, muito difundida no território americano, foi a responsável pela disseminação de um entendimento dualista da relação mente-corpo em psicossomática. A conceituação de neuroses vegetativas contribuiu para a manutenção de uma divisão entre patologias que poderiam ser estudas a partir da interação entre mente e corpo (as sete apresentadas acima) e aquelas que seriam manifestação de fatores alheios às subjetividades (viroses, neoplasias, entre outras). O que se seguiu foi a consolidação de uma visão segmentada entre patologias somáticas de fundo psicológico, cujos tratamentos poderiam lançar mão também de suporte psicoterápico, e as doenças orgânicas por excelência, essas objeto apenas da medicina tradicional. 
Apesar de não nos aprofundarmos no tema, um conceito específico do deve ser citado aqui, uma vez que se configura como primordial no campo psicossomático desenvolvido no Estados Unidos atualmente. O psiquiatra Peter Sifneos (1920 2008) criou o termo Alexitimia ( $a$ = não; lexis = palavra; thymós = emoção), cuja definição pode ser dada pela dificuldade de perceber, codificar e expressar os sentimentos. $\mathrm{O}$ autor foi levado à criação desse conceito ao observar o discurso de pacientes psicossomáticos e perceber neles esse estilo de embotamento afetivo, que os autores franceses denominaram de Pensamento Operatório tal como explicitado acima (Sifneos, 1973).

Essa característica seria um mecanismo de defesa do ego, com alta taxa de incidência em pacientes que passaram por experiências de grande trauma e se dá pela incapacidade de elaboração psíquica da experiência (Tenenbaum, 2017). Esse quadro não é específico de nenhuma doença, e pode estar presente com diferentes intensidades: desde a leve, onde há a impossibilidade de nomear um sentimento específico diante de alguma situação, até a ausência completa da nomeação de toda a afetividade (Sifneos, 1973).

No continente europeu um outro polo de pesquisa e atuação junto a doentes orgânicos se desenvolveu alguns anos posteriores a Chicago e se tornou hegemônico entre psicanalistas com interesse na área (Santos \& Peixoto Jr., 2019). Pierre Marty, foi o médico e psicanalista francês criador do que ficou conhecido como Instituto de Psicossomática de Paris (IPSO), ao lado de alguns eminentes colaboradores. Através do conceito de "neurose atual" de Freud, desenvolvida mais profundamente por Ferenczi, o grupo procurou compreender o adoecimento somático.

Para Marty (1993), o ser humano estaria constantemente diante do aparecimento e do fluxo tomado pelas excitações, tendo a necessidade de descarregá-las. Importante salientar que:

A noção de funcionamento mental empregada por Marty e seus colegas (...) trata-se do modelo freudiano, em que o psiquismo é visto como um aparelho que opera tendo como função possibilitar a descarga das tensões experimentadas pelo organismo, sobretudo aquelas provenientes das excitações pulsionais (Santos \& Peixoto Jr., 2019, p. 2).

Os franceses fizeram, assim, uma proposta de hierarquia do desenvolvimento das vias pelas quais se daria a descarga supracitada. $O$ bebê humano, em seu momento mais primitivo, lançaria mão da via orgânica para manifestar as excitações endógenas. Adiante, adquiriria a possibilidade de ação motora (consciente ou inconsciente) como ferramenta para descarga das tensões. E, como ponto evolutivo mais alto, teria a possibilidade de executar a descarga na forma de pensamentos, fantasias e sonhos. 
Falhas ou traumas no desenvolvimento impediriam a utilização dos processos mais evoluídos como o pensamento e a capacidade simbólica, surgindo como solução uma regressão à motricidade e às reações orgânicas. Nesse sentido, surge a importância do pré-consciente, um reservatório das representações, ligando as representações-coisa e as representações-palavra. Quanto maior a ligação das representação-coisa com palavra, maior seria a capacidade de utilização dos recursos simbólicos (Volich, 2010).

Marilia Aisenstein (2010) afirma que o conjunto de sintomatologia orgânica estaria relacionado à impossibilidade do aparelho mental em decodificar demandas internas. Ao se referirem aos doentes orgânicos, os autores franceses afirmavam que eles têm a peculiaridade de apresentar um tipo específico de pensamento, que foi denominado de pensamento operatório. Esse termo diz respeito a um funcionamento mental emocionalmente empobrecido, com predomínio das atitudes práticas, que não dá importância aos fatos presentes, é incapaz de projeções voltadas ao futuro e é pobre em simbolismo (Marty \& M'Uzan, 1962/1994).

O processo de adoecimento estaria em íntima relação com essa pobreza de recursos psíquicos, ou seja, uma dificuldade de mentalização, processo descrito como a forma pela qual o aparelho mental regula seu conteúdo energético, através de processos como simbolização e representação. Quantidade e qualidade das representações no pré-consciente definem a qualidade da mentalização, de forma que uma capacidade pobre de mentalização seria a via facilitadora para o escoamento das intensidades pulsionais no corpo físico.

As propostas da equipe de Paris versam sobre características relacionadas às intensidades psíquicas endógenas que visam descarga, tal como explicitadas na noção de mentalização, e à capacidade linguística, como no caso do conceito de pensamento operatório, modo de expressão verbal que não se pode dizer que está presente de maneira restrita aos ditos "pacientes psicossomáticos". A caracterização, por si só, de uma entidade nosológica específica segue o mesmo procedimento relativo às neuroses e psicoses: estrutura-se um tipo de funcionamento psíquico e o enrijece.

O desenvolvimento desse ponto de vista leva, em última análise, a uma apresentação das doenças orgânicas como produtos diretos de intensidades pulsionais desviadas de sua destinação ideal. É o corpo enquanto depósito e tela onde se guarda e pinta aspectos mentais. Se Descartes, ao apresentar a questão da diferença substancial entre mente e corpo, passou a ser criticado por ter criado uma ideia parecida com a de um fantasma dentro de uma máquina (Ryle, 1949/2009), Pierre Marty e seus seguidores acabaram por desenvolver a ideia de uma produção fantasmática - pulsional - que atua diretamente no corpo. Ao tentar explicar o adoecimento biológico a partir de pressões internas, os franceses deixaram de fora outros aspectos importantes da constituição humana: seu entorno social e suas relações (Santos \& Peixoto Jr., 2019). 
Pelo exposto até aqui, pode-se notar que os ideais contidos nas propostas dos Institutos de Chicago e Paris não esgotam o conhecimento psicossomático. Os interessados pela área psicossomática tiveram que levar adiante as investigações sobre o problema mente-corpo com a aquisição de novas ferramentas e tomando emprestado conhecimentos de diversas outras áreas do saber. Aqui lançaremos mão dos conhecimentos sobre o vínculo humano para tentar entender essa intrigante problemática milenar.

\section{ALgumas propostas teóricas sobre O VÍNCULO HUMANO}

Sigmund Freud iniciou uma nova maneira de se encarar o ser humano, modificando, de forma permanente, a maneira de se entender as manifestações individuais, relacionais e socioculturais. As noções intrapsíquicas freudianas, assentadas na ideia de pulsão, permitiram um enorme avanço no entendimento dos processos saudáveis e patológicos da mente humana. No que tange algumas vertentes da teoria psicanalítica, os objetos aos quais essas pulsões se direcionam são menos importantes do que o movimento em si feito por elas; importa mais a descarga, a busca pelo prazer e evitação do desprazer do que o relacionamento intersubjetivo de modo geral. Tem-se que o psiquismo, fundamentalmente inato, pressiona de dentro para fora buscando primordialmente a satisfação e diminuição da tensão.

Porém, cremos que o ser humano, acima de tudo, busca contato; engajamento com outras mentes; vínculo. Para além das noções eminentemente intrapsíquicas de Freud e alguns colaboradores, outros autores têm muito a contribuir para se pensar a gênese da mente e sua relação com o corpo. Aqui, sabendo da ampla gama de vertentes presentes no campo dos estudos sobre o vínculo humano, nos permitimos condensar as ideias de apenas alguns expoentes. Serão apresentados autores da chamada teoria das relações objetais, intersubjetividade e teria do apego que, com suas diferenças, apontam para um norte único: o desenvolvimento do bebê humano dá-se na relação com o outro. É nesse sentido que se torna necessária uma maior compreensão de suas ideias com o intuito de aprofundar o entendimento dos processos orgânicos sadios e mórbidos.

Para Lessem (2005), "o conceito mais fundamental da teoria da intersubjetividade é o de Campo Intersubjetivo. Isto se refere ao sistema psicológico formado por mundos subjetivos diferentemente organizados, interagindo reciprocamente" ( $p$. 3). Nesse sentido, a psicanálise procura esclarecer fenômenos que emergem dentro de um campo psicológico específico constituído pela interseção de duas subjetividades, com os fenômenos intrapsíquicos sendo entendidos no contexto dos mais amplos sistemas interacionais nos quais tomam forma (Stolorow \& Atwood, 1994). Para Kahtalian (2002): 
Grandes ideias, importantes desenvolvimentos na teoria e na prática clínica não mais derivam do modelo do impulsoinstintivo. As contribuições mais criativas e influentes derivam de uma perspectiva alternativa que considera relações com outros e não impulsos instintivos - a essência básica da vida mental. As teorias relacionais embora variadas e heterogêneas, diferindo uma das outras em muitos pontos importantes, têm contribuído para mudar a natureza da investigação e do tratamento em psicanálise (p. 3).

Sándor Ferenczi pode ser incluído como um dos precursores da teoria de relações objetais. Contemporâneo de Freud, o analista húngaro propôs significativas mudanças na técnica psicanalítica além de se debruçar sobre o tratamento de pacientes mais graves se comparados às condições neuróticas clássicas avaliadas por Freud. Além disso, o autor húngaro foi o responsável por dar subsídios a autores como Franz Alexander, já apresentado, Michael Balint e Donald Winnicott, melhor explorados adiante.

Ferenczi preconizava a função do ambiente no desenvolvimento do infante. Nesse sentido, postulava que crianças precisavam ser bem acolhidas com a finalidade de se desenvolverem de maneira eficaz. Caso contrário, diante de um ambiente falho e pouco acolhedor às suas necessidades, a criança, diante da ação da pulsão de morte, poderia lançar mão de meios orgânicos para adoecer. O autor húngaro (1929/2011) afirma que:

Queria apenas indicar a probabilidade do fato de que crianças acolhidas com rudeza e sem carinho morrem facilmente e de bom grado. Ou utilizam um dos numerosos meios orgânicos para desaparecer rapidamente ou, se escapam a esse destino, conservarão um certo pessimismo e aversão à vida (p. 58).

Dessa forma, compreende-se que do ponto de vista ferencziano o indivíduo poderá lançar mão de seu todo psicossomático para lidar com as falhas ambientais. Ainda na obra referida acima, Ferenczi apresenta a ideia de que a relação mãebebê serve como vacina para lidar com os problemas existenciais no longo percurso da vida. O autor mostra que "a força vital que resiste às dificuldades da vida não é muito forte no nascimento. Ela se reforça após a imunização progressiva contra os atentados físicos e psíquicos através de um tratamento e educação conduzidos com tato" (p. 59).

Ou seja, reside na obra de Ferenczi, entre outros pontos importantes, a possibilidade de se olhar para afecções do tipo somático a partir do entendimento da função materna, através da qual se dá o desenvolvimento emocional da criança. Peixoto Jr. (2013), ao apresentar a importância ferencziana nos dias atuais, diz que: 
Os problemas da prática relacionados com os chamados "casos difíceis", que sempre chamaram a atenção do aguçado olhar clínico ferencziano, parecem ter se tornado cada vez mais frequentes em nossos dias. Isso pelo fato de os esquemas teóricos e clínicos, dos quais a psicanálise dispunha desde os seus primórdios até a primeira metade do século passado, terem se tornado insuficientes diante da singularidade das formas de subjetivação e de sofrimento psicossomático, os quais pareciam não mais se encaixar na grade conceitual previamente estabelecida (p. 96-97).

Conforme veremos a seguir, após o seu início com Ferenczi, que inaugurou a possibilidade de entender o ser humano a partir do primado das relações objetais, outros autores se apresentarão como expoentes de primeira linha dos estudos sobre os vínculos. Depois do falecimento do analista húngaro, estando isolado em Edimburgo, na Escócia, o médico e psicanalista William R. D. Fairbairn tornou-se um dos primeiros a combinar a metapsicologia com a teoria das relações de objeto. Fairbairn entendia o ego do bebê como inteiro desde o nascimento, possuindo "a capacidade de se relacionar com objetos externos inteiros" (Ogden, 2015, p. 146). É através de dificuldades na relação com a mãe que, utilizando-se do mecanismo de clivagem, a criança ainda muito nova passa a separar partes desse ego.

Ou seja, é a relação com esse objeto que é reprimida na tentativa de controlá-lo e modificá-lo. Uma conclusão que se pode extrair daí é que a introjeção não é propriamente do objeto, mas sim da relação, e inclusive no que ela tem de fracasso, não de sucesso. As relações primordiais que se passassem de forma positiva, sem rupturas ou ausências mais significativas por parte do objeto (especificamente a mãe) não precisariam sofrer o processo de introjeção.

O ponto nodal do pensamento de Fairbairn é fundamentalmente o seguinte: a pulsão não visa a descarga, como afirmava Freud; ela visa o vínculo (Peixoto Jr., 2014). Ou seja, o ser humano nasce para se relacionar, para se encontrar com outros seres humanos, e nesse processo de encontro/desencontro é que a mente vai se formando de forma saudável ou, quando os encontros são qualitativamente problemáticos, de forma patológica. Os indivíduos, desde tenra infância, teriam necessidade de buscar objetos, o que caracterizaria a finalidade da tensão libidinal (Fairbairn, 1946/1980). Portanto:

Fairbairn propõe um significativo rompimento com o modelo pulsional de Freud. Isso decorre da natureza relacional do ego, o qual (para Fairbairn) simplesmente perde o sentido caso não esteja ligado a algum objeto, correndo inclusive o risco de deixar de existir. Em um cenário ideal, o ego infantil culminaria em um ego unitário, integral, dotado de energia própria buscando, a todo tempo, relações com objetos externos, totais, reais. No 
entanto, quando o sujeito se depara com relações insatisfatórias, o desenvolvimento é perturbado (Nunes \& Peixoto Jr., 2019, p. 75-77).

A obra de Fairbarn é de extrema complexidade justamente pela virada paradigmática que propõe. O que se extrai da obra desse autor é a inovadora proposta de se conceber a gênese mental, ou seja, o surgimento de um indivíduo total, a partir das suas relações com os objetos-ambiente que o cercam. Sem vínculo não há subjetividade; sem vínculo não há integração somatopsíquica.

Diferentemente de Fairbairn, que se mantinha isolado da efervescência da Sociedade Britânica, Michael Balint estava no centro do desenvolvimento do Middle Group, conjunto de analistas que se diferenciavam e mantinham-se alheios às controvérsias entre os grupos Kleiniano e Anna-Freudiano. Balint foi um psicanalista húngaro que migrou para a Inglaterra nos anos 50 , tendo trabalhado desde cedo em Hospitais Gerais - primeiro na Hungria, depois na Alemanha e por fim na Tavistock Clinic, de Londres (Peixoto Jr., 2013). Foi nesse contexto, inclusive, que o autor desenvolveu seus estudos sobre a relação médico-paciente e criou os chamados Grupos Balint, reunião através das quais, tendo como sustentação básica a noção de contratransferência, os clínicos poderiam discutir e reconhecer aspectos da própria subjetividade presentes na prática assistencial (Balint, 1957/1988).

Balint sustentou seu trabalho teórico em cima dos estudos das relações primitivas da criança com o seu entorno. A partir de seu trabalho clínico, Balint formulou a ideia de "amor primário", um estado, presente a partir do nascimento, de "intensa relação com o seu entorno, tanto biológica, quanto libidinalmente" (Balint, 1968/1993, p. 61). A base dessa relação primeira é a díade mãe-bebê desde o útero, no qual ambos se encontram em sintonia. Diz o autor que "embora já haja indivíduo, que está cercado, quase flutua, em substâncias sem fronteiras exatas; as substâncias e o indivíduo se interpenetram; isto é, eles vivem em uma mistura harmoniosa" (Balint, 1959/1987, p. 67).

Balint, então, procura diferenciar dois tipos de regressão na relação transferencial: a regressão maligna, marcada por uma voracidade e a regressão benigna que se direciona para o "novo começo", resultado da regressão benigna, implicando possibilidades para novas formas de investimentos em si mesmo e nos objetos externos (Balint, 1959/1987). À medida em que se dá o desenvolvimento, a passagem da fase do amor primário para o direcionamento pulsional a objetos, falhas podem ocorrer.

Assim surge o conceito de "falha básica". Ela designa uma área da mente caracterizada por uma falha - não um conflito, como existente na área edípica -, por um descuido por parte de um cuidador muito importante e primitivo no desenvolvimento do indivíduo. É "básica", por sua vez, porque essa falha mostra sua influência por toda a estrutura psicológica da pessoa e pode ser percebida no adoecimento neurótico, psicótico e psicossomático. Balint (1993), afirmou que "o 
conceito de falha básica nos permite compreender as diversas neuroses, transtornos de caráter e doenças psicossomáticas como sintomas de uma mesma entidade etiológica" (p. 19). Em seu livro, Peixoto Jr. (2013) afirma que o autor húngaro foi levado a "compreender os comprometimentos básicos na maneira como o ambiente pretende se encarregar do ser humano nos seus momentos mais primitivos e que se constituem na causa fundamental das mais diversas doenças, não apenas psicológicas como também físicas" (p. 3).

Adiante, no mesmo livro, o autor continua:

O adjetivo "básica" significa ainda que o autor se refere (...) a influência dessa falha ou eficiência estende-se de maneira ampla quanto aos seus efeitos. Provavelmente ela perpassa toda a estrutura somatopsíquica da pessoa, envolvendo em graus diferenciados mente e corpo. A discrepância entre as necessidades biopsíquicas de um indivíduo e os cuidados material, psicológico ou afetivo disponibilizados em momentos relevantes pelo entorno (no decorrer de fases precoces de sua formação) cria uma situação de deficiência cujas consequências posteriores parecem ser apenas em parte reversíveis (Peixoto Jr., 2013, p. 63).

Pelo exposto, tomamos como possível considerar que uma dessas "consequências" é a possível cronificação de um modo mórbido de responder ao ambiente, levando, inclusive, ao adoecimento físico. Essa ideia só é possível a partir de uma visão na qual a formação individual é, desde os seus primórdios, integral, não havendo diferença entre corpo e mente. Melhor dizendo, corpo e mente estabelecem-se como única substância, apesar de apresentarem atributos e formas de expressão distintos. O desenvolvimento humano é, como visto na obra de Balint, produto da interação psicossomática e ambiental.

Já para Wilfred Bion (1973), o pensamento é anterior ao pensar, sendo o primeiro um problema imposto ao indivíduo fazendo com que surja a necessidade do segundo. Além disso, o autor faz a formulação de que o pensar é uma função de um elo emocional, ou seja, o pensar só se desenvolve a partir de uma relação de objeto (Marinho, 1997).

Nesse sentido, o texto "Cesura", de 1977, foi feito a partir da célebre frase de Freud de que "existe muito mais continuidade entre a vida intrauterina e a primeira infância do que a impressionante cesura do nascimento pode nos fazer acreditar" (1926/1974, p.162). Nesse sentido, a ligação entre mãe e filho, a despeito do corte feito no ato do parto, mantém-se de outras maneiras como parte constitutiva no processo de individuação.

Em "Notas sobre o mecanismo esquizoide", de 1946, Melanie Klein apresenta as características do ego primitivo, os sofrimentos e as relações objetais que daí 
advém. Nesse sentido, demonstra o mecanismo de cisão e os acontecimentos decorrentes e contíguos ao mesmo. É nesse texto que se dá a primeira aparição do conceito de "identificação projetiva", da seguinte maneira:

"Muito ódio contra partes do self é agora dirigido contra a mãe. Isso leva a uma forma particular de identificação que estabelece o protótipo de uma relação de objeto agressiva. Sugiro o termo identificação projetiva para esses processos" (Klein, 1946/2006, p. 27).

Porém, não se trata apenas de um processo em que partes ruins do self são projetadas na figura da mãe; há também o envio de partes boas desse self ainda em formação, tendo a função de presentes dados à figura materna. Esse mecanismo de identificação através da projeção de sentimentos amorosos será de suma importância para as relações objetais na vida subsequente desse bebê.

Bion vê a identificação projetiva como a mais importante forma de interação entre mãe e bebê; entre paciente e terapeuta. Ou seja, para além do que formulava Klein, não se trata apenas uma fantasia, mas também uma manipulação de uma pessoa sobre a outra; uma interação interpessoal. A experiência da identificação projetiva no receptor é como se ele tivesse pensamentos que não são seus (Ogden, 1982).

O que até então era considerada um mecanismo que expressava uma fantasia e, portanto, um fenômeno intrapsíquico, passou também a ser considerada como um fenômeno interpsíquico, ou seja, um meio de comunicação. Em relação as considerações de Bion, Ribeiro (2006) afirma que:

"A identificação projetiva [para Bion] é compreendida como um elo, com um aspecto comunicativo, sendo que as qualidades psíquicas da mente da mãe e do analista são consideradas. É uma compreensão que expande o conceito postulado por Klein. Bion ressalta a função de comunicação de estados mentais e considera as condições psíquicas do receptor da identificação projetiva. A identificação projetiva passa a ser compreendida como um elo primordial entre bebê e mãe e entre analista $e$ paciente" (p. 17).

Assim, é a identificação projetiva que possibilita à criança se sentir entendida pela mãe/ambiente. Em suma, a gênese mental se dá a partir da relação mãe/bebê através, primordialmente, do conceito supracitado. Como diz Figueiredo (2020), a expansão mental se dá obrigatoriamente pela presença do outro real. Especificamente a mãe deve oferecer ao filho "suas capacidades de elaboração psíquica" (p. 162) para que essa expansão ocorra. 
Também na Inglaterra, um outro autor surge como imprescindível no estudo do desenvolvimento infantil e das possíveis consequências somatopsíquicas de um entorno pouco acolhedor. Junto a Balint e outros do Middle Group, o pediatra e psicanalista britânico Donald Winnicott estabeleceu-se enquanto referência para o estudo dos caminhos normais e patológicos que o bebê humano pode trilhar.

Para Winnicott o ser humano se estruturará enquanto todo psicossomático somente através de um ambiente que favoreça esse processo. Além disso, o indivíduo estará em eterna dependência do ambiente e seu caminho rumo a independência relativa possui algumas nuances. Winnicott (1956/2000a) afirma que, após o nascimento, a criança apresenta-se em estado de "dependência absoluta", o que exige um alto grau de adaptação do ambiente às suas necessidades. Nesta fase, a mãe se coloca ativamente frente a todo tipo de necessidade do bebê e pode, em virtude do conjunto de memórias, imaginação e seu narcisismo próprios, reconhecer e suprir possíveis necessidades dele. Além disso, o autor afirma que: "O fornecimento de um ambiente suficientemente bom na fase mais primitiva capacita o bebê a começar a existir, a ter experiências, a constituir um ego pessoal, a dominar os instintos e a defrontar-se com as necessidades inerentes à vida" (Winnicott, 1956/2000a, p. 403).

Adiante, no estado de "dependência relativa", a criança passa a ganhar consciência de sua condição existencial, devendo surgir a capacidade de adaptação do bebê a possíveis falhas, caso tudo corra bem no ambiente em que ela é cuidada. Segundo o autor, como cada bebê possui uma capacidade específica de suportar a ausência da mãe o aparecimento de ansiedades se dará em intensidade e momentos diferentes. Dependendo do tempo dessa ausência e da intensidade do sofrimento psíquico gerado, o bebê poderá vir a ter dificuldades em estruturar um ego mais consistente (Winnicott, 1963/2008). Por fim, o último estágio é o de "independência relativa". Nesse momento, a criança passa a se defrontar com o mundo externo e suas dificuldades, dando início a seus relacionamentos interpessoais. Uma vez que a independência nunca é conseguida em sua totalidade, é nesse estágio que todos os indivíduos se mantêm em toda a vida: os seres humanos se mantêm em um processo de amadurecimento nunca finalizado, sempre dependentes em certa medida e em certas situações de vínculos e relações com o ambiente externo.

Falhas decorrentes de um ambiente incapaz de se adaptar às necessidades dos estágios mais iniciais de dependência do bebê podem vir a gerar desconforto de níveis altíssimos os quais incluem acometimentos somáticos. Assim, para Winnicott, corpo e psiquê seriam afetados conjuntamente diante de dificuldades existenciais no relacionamento (Winnicott, 1954/2000b). O autor mostra grande originalidade no assunto aqui debatido, sobretudo em sua diferenciação acerca dos conceitos de psiquê e mente. Diz ele:

Existe o soma e a psiquê. Existe também um interrelacionamento de complexidade crescente entre eles, e uma 
organização deste relacionamento proveniente daquilo que chamamos mente. Podemos discernir entre funcionamentos do corpo, da psiquê e da mente (...) o soma e a psiquê é que são opostos. A mente constitui uma ordem à parte (Winnicott, 1954/1990, p. 29).

Poucas páginas depois, o autor continua dizendo que "a base da psiquê é o soma e, em termos evolutivos, o soma foi o primeiro a chegar. A psiquê começa como uma elaboração imaginativa das funções somáticas (p. 37). Ou seja, a partir do corpo biológico é que a psiquê, nos termos winnicottianos, começa a se desenvolver. Essa visão nos remete à concepção monista não redutiva brevemente citada na introdução.

Em caso de um ambiente que não permita a integração do indivíduo, bem como facilite cisões do ego, podem se desenvolver doenças psicossomáticas. Esse termo, para o autor, não tem tanto a ver com os sintomas de ordem física expressos nas doenças orgânicas, mas justamente tem a ver com essa cisão, com dissociações egóicas. Winnicott (1964/1989) mostra que, em última análise, o adoecimento físico passa, pelo menos, por distúrbios que envolvem o relacionamento intersubjetivo.

Outro autor de grande importância para o entendimento do vínculo humano foi o psicanalista inglês John Bowlby, com sua contribuição significativa para a construção da Teoria do Apego. Ele apresentou a hipótese de bebês experimentarem um relacionamento contínuo, íntimo e cálido com sua mãe (ou mãe substituta permanente) cuja falta pode acarretar significativas e irreversíveis consequências para a saúde mental e física. Interessado em entender a importância do vínculo diádico em bebês, entre os primeiros meses e poucos anos de vida, empreendeu um estudo interdisciplinar que, embora tivesse o arcabouço teórico da psicanálise enquanto linha mestra, agrupou os conhecimentos da etologia e da neurobiologia em sua observação teórico-clínica (Bowlby, 1951).

Seu ponto inicial foi o entendimento das reações de bebês à perda da figura materna, de modo provisório ou não. Para Bowlby (1969/2002), bebês precisam apegar-se a figuras de seu ambiente desde muito cedo, em um processo que perpassa desde os 6 meses aos 2 anos de idade. Esse apego tem como característica psicodinâmica a garantia da formação de um espaço de segurança, através do qual a criança pode expandir seu aparato psíquico e social.

Partindo das ideias de Freud sobre o conceito de trauma, o autor inglês postula que a separação da mãe em tenra idade funciona para a criança como causa etiológica no que diz respeito às inibições sociais, psicopatologia em geral, incluindo psicoses e doenças orgânicas. Bowlby (1969/2002) aproveita para fazer críticas ao conceito de "energia psíquica" utilizado por Freud. 
Enquanto o fundador da psicanálise se baseou nessa ideia para explicar o funcionamento mental pré e pós-traumático, Bowlby sustenta que é pouco plausível a existência desse conteúdo energético, tendo como sustentação teórica os estudos neurobiológicos mais atuais ao seu tempo. Psicanalistas interessados nos estudos sobre as relações de objetos também influenciaram Bowlby. Entretanto, ele manifestou certas dúvidas sobre o entendimento psicanalítico da época sobre a relação de bebês com sua vida de fantasias internas, propondo maior enfoque nos fatores externos. Nesse sentido, para ele, a psicanálise deveria passar a aceitar o apego como um vínculo psicológico ele próprio, não algo derivado da sexualidade, por exemplo (Bowlby, 1951). Além disso, o autor criticou a visão do desenvolvimento humano através de fases lineares. Pensando de forma diferente, Bowlby (1969/2002) acreditava que infinitas possibilidades - associando fatores interpessoais e ambientais - estariam presentes dentro do desenvolvimento normal da criança, bem como em suas patologias mentais e orgânicas.

Assim, a "Teoria do Apego" propõe que a qualidade do cuidado é a chave para o apego seguro ou inseguro. Na ausência de cuidadores disponíveis e sensíveis, parece que algumas crianças são particularmente vulneráveis ao desenvolvimento de distúrbios de apego. Em pesquisas psicofisiológicas sobre o apego há evidências de que a qualidade do cuidado molda o desenvolvimento dos sistemas neurológicos que regulam o estresse (Bowlby, 1969/2002). Nesse sentido, pode-se postular e avaliar a pertinência das correlações entre apegos seguros, desenvolvimento do ego infantil e sua capacidade de elaborar situações da vida adulta. Aliado a outros campos de saber, o autor conseguiu demonstrar a relevância dos vínculos iniciais da vida com a segurança e o bom desenvolvimento mental e social posteriores, inclusive do ponto de vista orgânico.

Todos os autores utilizados como sustentáculo dessa ideia procuraram justamente compreender o desenvolvimento do aparato psíquico através da relação com outros e o ambiente. A partir daí, supuseram a possibilidade de adoecimento, não apenas psicológico, mas também somático, em virtude de dificuldades nessas relações, seja em estágio inicial - infância - ou na vida adulta. Diante do material apresentado, acredita-se ser possível traçar as relações entre as falhas afetivas/ambientais e o adoecimento somático.

A importância do vínculo diádico ganhou força dentro da teoria psicanalítica, como relação primordial para o desenvolvimento emocional e formas de subjetivação subsequentes. Em solo brasileiro alguns psicanalistas se dedicaram a unir os postulados básicos dos estudos sobre o vínculo humano e a concepção de Homem que não necessite mais de uma separação entre os conceitos de psiquê e soma. No que tange ao adoecimento físico, sobretudo, esses autores surgiram como inovadores.

\section{PSICOSSOMÁTICA NO BRASIL: A ANTROPOGÊNESE DO ADOECIMENTO}


No Brasil, as pesquisas de Danilo Perestrello o levaram a considerar que não seria possível falar em doenças psicossomáticas, pois o ser humano é uma entidade psicossomática. Ainda nesse sentido, a expressão "paciente psicossomático" não daria conta de explicar a íntima relação entre psiquismo e corpo biológico, chegando até mesmo a atrapalhar a prática assistencial. Seria, por fim, um pleonasmo (Perestrello, 1974/2006). O autor, ao lado de Abram Eksterman, introduziu noções oriundas da filosofia, etologia e psicologia do vínculo nas suas concepções sobre a relação mente-corpo (Tenenbaum, 2017). Assim, seguindo as diretrizes hipocráticas, o que existem são doenças antropogênicas. Ou seja, o adoecimento, de qualquer ordem, seria um produto inerente à existência humana. $\mathrm{O}$ autor mostra que:

A doença, portanto, não é algo que vem de fora e se superpõe ao homem, é sim um modo peculiar de a pessoa se expressar em circunstâncias adversas. É, pois, como suas várias outras manifestações um modo de existir, ou melhor, de coexistir, já que, propriamente, o homem não existe, coexiste. E como o ser humano não é um sistema fechado, todo o seu ser se comunica com o ambiente, com o mundo. E mesmo quando aparentemente não existe comunicação, isto já é uma forma de comunicação, como o silêncio, às vezes, é mais eloquente do que a palavra (Perestrello, 1974/2006, p. 43).

Ainda nesse âmbito, Eksterman (1975) afirma que o ideal é que a psicanálise renuncie ao pensamento causal outrora em voga, que tentou entender as enfermidades somáticas a partir de uma psicogênese, ou seja, tomando o psiquismo como causa das doenças físicas. O objetivo final é ver o doente como uma pessoa, em sua totalidade e forma de se relacionar com o mundo a sua volta. Mas o próprio conceito de "pessoa" deve ser explicado e problematizado. Eksterman (1974/2006) diz que pessoa não designa um fato, mas sim uma experiência. Nesse sentido, uma pessoa só existe no encontro com outra pessoa; é o produto da interação entre dois sujeitos e não entre sujeito e objeto. É uma experiência humana e só existe na relação humana, e o que se revela numa relação é o drama dos envolvidos nela. Deve-se, então, tomar a psicanálise como método para explicar a interação humana. É o que Eksterman (1974/2006) mostra:

O esquema de funcionamento do ato psicanalítico é o de transformação psíquica e pretende ampliar a capacidade de organização pessoal diante do outro e do espaço social. Não é um ajustamento, no sentido de conformar o sujeito em seu espaço social, mas de instrumentalizá-lo com esses recursos mentais através da ampliação da consciência (p. 48-49). 
Assim, o autor produziu o que se chama "História da Pessoa" para ajudar médicos a entenderem melhor seu paciente. Aqui nos permitimos aventar a possibilidade de transportar esse método para o encontro terapeuta-paciente sobretudo nos casos que envolvem o adoecimento físico. A liberdade dada ao paciente de poder falar sobre a doença que enfrenta é o diferencial em relação à simples escuta de respostas a partir de perguntas gerais. Essa ferramenta é caracterizada como uma anamnese não dirigida, um instrumento de reconhecimento da pessoa, cujos objetivos são (i) recolher a biografia do doente dentro de um diálogo clínico o mais espontâneo possível; (ii) conhecer as circunstâncias nas quais ocorreram o atual e os antigos adoecimentos e (iii) conhecer a maneira pela qual o doente interage com o médicos, equipe e família.

Tal anamnese visa colher dados cujo conteúdo seja rico em significado, e não apenas um mero registro formal de acontecimentos. O foco não deve estar na cronologia e objetividade dos fatos relatados, mas sim em como o paciente os viveu. No âmbito terapêutico, a importância desse método reside no fato de não partir de uma ideia causal entre personalidade e doença, ou de uma visão de simbolismo do sintoma físico através do escoamento de tensões endógenas, mas de estabelecer um vínculo terapêutico verdadeiramente capaz de permitir um maior fluxo dos conteúdos subjetivos presentes na relação.

Seria nesse balanço relacional, através de um vínculo solidamente erigido, que as associações se sucederiam e um espaço de segurança permitiria a redução das tensões endógenas e exógenas. O que está em questão, nesse caso, é a garantia de que na relação terapêutica as forças vitais - aqui consideradas desde o bom fluxo de conteúdos psíquicos, passando pelas produções simbólicas até a sensação de segurança garantidora de um funcionamento corporal homeostático - estariam mais presentes.

A visão apresentada por esses expoentes do pensamento psicossomático brasileiro é de extrema singularidade. Alicerçados em bases filosóficas e antropológicas, trouxeram para o campo de debate a noção, diversas vezes esquecida, do ser humano enquanto um sistema complexo e de permanente contato com fatores endógenos e, sobretudo, exógenos. Apresentaram o Homem como um todo psicossomático, aberto ao mundo externo e às relações, impactando e sendo impactado por ambos. Assim, o que Danilo Perestrello e Abram Eksterman mostram é que se torna mandatório escutar o doente de forma única e singular. Urge construir um diálogo clínico que permita à dupla terapeuta-paciente erigir e desenvolver um encontro verdadeiramente humano. O que é necessário, por fim, é o estudo da pessoa também com seu mundo relacional, que tem o poder de atingir o presente em grande ou menor escala.

O presente artigo, tomando como base esse pensamento, buscou iniciar um debate tendo premissas estritamente teóricas sobre como o Homem, essa integridade psicossomática, está sujeito a desorganizações a partir de problemas 
que dizem respeito às relações. Esses problemas, pensamos, podem contribuir para o adoecimento corporal, além de psíquico.

Falhas no cuidado ou situações do presente que influenciam os relacionamentos intersubjetivos podem ser pensados como agentes etiológicos de doenças físicas. Ora, se a mente emerge a partir das relações, é através de rupturas mais ou menos difíceis nessas relações que a mente pode vir a se desorganizar. Significa dizer que falhas relacionais - passadas ou presentes - podem ser pensadas como disparadores de quebra homeostática do organismo. Tendo esse facilitador, o acometimento orgânico se torna mais um caminho possível. Ao associar o embasamento teórico advindo dos autores que se dedicaram aos estudos sobre o vínculo com os postulados de nossos compatriotas, pensamos ser possível iniciar a construção de um olhar para o adoecimento físico que não seja inerentemente dualista.

\section{CONSIDERAÇÕES FINAIS}

O modelo de funcionamento mental dinâmico proposto desde Freud abriu caminho para a interlocução entre diversos saberes: a mente deixou de ser uma entidade separada do corpo e, nesse sentido, foi possível iniciar estudos e hipóteses sobre a íntima ligação entre os fatores endógenos e exógenos no desenvolvimento humano. Contemporâneos e autores posteriores a Freud passaram a conceber o desenvolvimento humano a partir da interação com os outros e o ambiente como um todo. Não mais solipsista, o bebê humano surge a partir das relações estabelecidas com o mundo-ambiente.

As intervenções psicoterápicas junto a doentes orgânicos precisam estar filiadas à alguma teoria sobre a relação mente-corpo. Dessa forma, é preciso buscar as bases sobre as quais tais teorias se assentam. Nesse artigo, levantamos a possibilidade de junção entre postulados sobre o problema mente-corpo e as ideias advindas de ramos da psicanálise que se debruçaram sobre o aspecto relacional a fim de estabelecer uma forma talvez mais autêntica de pensar o adoecimento físico.

Por fim, deve-se buscar o entendimento da doença como um acontecimento que toma seu curso em um sistema onde fatores externos e internos se conjugam e se influenciam. Ou seja, a doença em si já é uma forma de se relacionar e reagir ao mundo sem que haja a necessidade de pensá-la enquanto símbolo de algo recalcado ou característica rígida de determinada personalidade. A doença física é, portanto, um acometimento psicossomático ela própria, pois ocorre em um sistema complexo, aberto e dinâmico. E apenas uma intervenção que leve em conta essas características pode, de fato, contribuir para o restabelecimento integral do indivíduo. 


\section{REFERÊNCIAS}

Aisenstein, M. (2005). Abordagem psicodinâmica do paciente psicossomático. In C. L. Eizirik, R. W. Aguiar \& S. S. Schestatsky (Eds.), Psicoterapia de orientação analítica: fundamentos teóricos e clínicos (pp. 659-668). Porto Alegre, RS: Artes Médicas.

Aisenstein, M. (2010). The mysterious leap of the somatic into the psyche. In M. Aisenstein \& E. R. Aisemberg (Eds.), Psychosomatics today: a psychoanalytic perspective (S. Jaron, Trad., pp. 4762). London: Karnac.

Alexander, F. (1989). Medicina psicossomática: princípios e aplicações. Porto Alegre, RS: Artes Médicas.

Balint, M. (1987). Thrills and regressions. Connecticut: International Universities. (Trabalho original publicado em 1959).

Balint, M. (1988). O médico, seu paciente e a doença. Rio de Janeiro, RJ: Atheneu. (Trabalho original publicado em 1957).

Balint, M. (1993). A falha básica. Porto Alegre: Artes médicas. (Trabalho original publicado em 1968).

Bion, W. (1973). Conferências brasileiras. Rio de Janeiro, RJ: Imago.

Bion, W. (1977). Ataques al vinculo. In W. Bion, Volvendo a pensar. Buenos Aires: Paidós (Publicado originalmente em 1959).

Bowlby, J. (1951). Maternal care and mental health. Geneva: World Health Organization.

Bowlby, J. (2002). Apego e perda: a natureza do vínculo. São Paulo, SP: Martins Fontes. (Trabalho original publicado em 1969).

Capra, F. \& Luisi, P. L. (2015). A visão sistêmica da vida. São Paulo, SP: Cultrix.

Cheniaux, E. \& Lyra, C. E. (2014). The dialog between psychoanalysis and neuroscience. Trends in Psychiatry and Psychotherapy, 36(4), 186-192. doi:10.1590/2237-6089-2014-0010

Eksterman, A. (1975). Psicanálise, Psicossomática e Medicina da Pessoa. Relatório Oficial do I Encontro Argentino-Brasileiro de Medicina Psicossomática. Buenos Aires.

Eksterman, A. (2006). Introdução. In D. Perestrello (Ed.), A medicina da pessoa (pp. 7-25). Rio de Janeiro, RJ: Atheneu. (Trabalho original publicado em 1974).

Eksterman, A. (2010). Medicina psicossomática no Brasil. Porto Alegre, RS: Artmed.

Engel, G. (1962). Psychological development in Health and Disease. Philadelphia: W. B. Sauders.

Engel, G. (1967). The concept of psychosomatic disorder. Journal of Psychosomatic Research, 11(1), 39.

Fairbairn, W. R. D. (1980). Relações objetais e estrutura dinâmica. In W. R. D. Fairbairn, Estudos Psicanalíticos da Personalidade (pp. 108-119). Rio de Janeiro, RJ: Interamericana. (Trabalho original publicado em 1946).

Ferenczi, S. (2011). A criança mal acolhida e sua pulsão de morte. In S. Ferenczi, Obras completas (Psicanálise - IV, pp. 55-60). São Paulo, SP: Martins Fontes. (Trabalho original publicado em 1929).

Figueiredo, L. C. (2020). A falta que Bion faz. Revista Brasileira de Psicanálise, 54(1), 157-170.

Freud, S. (1974). Estudos sobre a histeria. Rio de Janeiro, RJ: Imago. (Trabalho original publicado em 1895).

Freud, S. (1974). Inibições, sintomas e angústia. Rio de Janeiro, RJ: Imago. (Trabalho original publicado em 1926).

Gurfinkel, D. (2017). Relações de objeto. São Paulo, SP: Blucher.

Jones, E. (1957). Sigmund Freud: life and work. Londres: Hogarth Press.

Kahtalian, A. (2002). A teoria da intersubjetividade na psicanálise contemporânea. XXIV Congresso Latinoamericano de Psicanálise. Montevideo: Uruguai.

Klein, M. (2006). Notas sobre alguns mecanismos esquizoides. Rio de Janeiro, RJ: Imago. (Trabalho original publicado em 1946).

Lessem, P. (2005). Self-psychology: an introduction. Lanham: Jason Aronson Inc.

Lipowski, T. (1977). Psychosomatic medicine in the seventies: an overview. American Journal of Psychiatry, 134(3), 233-244. doi:10.1176/ajp.134.3.233

Luchina, I. L. (1971). La interconsulta médico-psicológica en el marco hospitalario. Buenos Aires: Nueva Visión.

Marty, P. \& M'Uzan, M. (1994). O pensamento operatório. Revista Brasileira de Psicanálise, 28(1), 165 174. (Trabalho original publicado em 1962).

Marty, P. (1993). A psicossomática do adulto. Porto Alegre, RS: Artes Médicas.

Maslin, K. T. (2009). Introdução à filosofia da mente. Porto Alegre, RS: Artmed.

Mello Filho, J. (1979). Concepção Psicossomática: Visão Atual. Rio de Janeiro, RJ: Tempo Brasileiro. 
Nunes, G. C. \& Peixoto Junior, C. A. (2019). A experiência esquizoide segundo Fairbairn e Guntrip. Revista Ágora - Estudos em Teoria Psicanalítica, 22(1), 75-86.

Ogden, T. (1982). Projective Identification and psychotherapeutic technique. Lanham: Jason Aronson Inc.

Ogden, T. (2015). A matriz da mente: relações objetais e o diálogo psicanalítico. Londres: Karnac Books.

Peixoto Jr., C. A. (2013). Michael Balint: a originalidade de uma trajetória psicanalítica. Rio de Janeiro, RJ: Revinter.

Peixoto Jr., C. A. (2014). Personalidade, relações objetais e esquizoidia na obra de Ronald Fairbairn. Interação em Psicologia, 18(1), 85-94. doi:10.5380/psi.v18i1.28751

Perestrello, D. (2006). A medicina da pessoa. Rio de Janeiro, RJ: Atheneu. (Trabalho original publicado em 1974).

Ribeiro, M. (2016). Uma reflexão conceitual entre identificação projetiva e enactment. Cadernos de Psicanálise, 38(35), 11-28.

Ryle, G. (2009). The concept of mind. Londres: Routledge. (Trabalho original publicado em 1949).

Santos, L. N. \& Peixoto Junior, C. A. (2019). O adoecimento somático em Ferenczi, Groddeck e Winnicott: uma nova matriz teórica. Psicologia: Ciência e Profissão, 39, 1-14. doi: 10.1590/1982-3703003182306.

Sifneos, P. (1973). The prevalence of 'alexithymic' characteristics in psychossomatics patients. Psychotherapy and Psychossomatics, 22(2), 255-262. doi:10.1159/000286529

Stolorow, R. D. \& Atwood, G. E. (1984). Toward a science of human experience. Lanham: Jason Aronson Inc.

Tenenbaum, D. (2013). Da Medicina à Psicanálise: o corpo e a pesquisa psicossomática. Mesa Redonda "O Corpo: do Discurso Médico à Psicanálise". Rio de Janeiro, RJ: Universidade Santa Úrsula. (Trabalho original apresentado em 1993).

Tenenbaum, D. (2017). As principais tensões psicológicas presentes na prática assistencial hospitalar: uma pesquisa em psicologia hospitalar utilizando a hermenêutica psicanalítica. Curitiba, SC: Appris Editora.

Volich, R. M. (2007). Fundamentos psicanalíticos da clínica psicossomática. In R. M. Volich, F. C. Ferraz \& M. C. Arantes (Eds.), Psicossoma II - Psicossomática Psicanalítica (pp. 17-31). São Paulo, SP: Casa do Psicólogo.

Volich, R. M. (2010). Psicossomática. São Paulo, SP: Casa do Psicólogo.

Winnicott, D. W. (1989). Psychosomatic disorder. In C. Winnicott, R. Shepherd \& M. Davis (Eds.), Psychoanalytic explorations. London: Karnac. (Trabalho original publicado em 1964).

Winnicott, D. W. (1990). Natureza humana. Rio de Janeiro, RJ: Imago. (Trabalho original publicado em 1954).

Winnicott, D. W. (2000a). A preocupação materna primária. Rio de Janeiro, RJ: Imago, 2000. (Trabalho original publicado em 1956).

Winnicott, D. W. (2000b). Aspectos clínicos e metapsicológicos da regressão no contexto analítico. Rio de Janeiro: Imago. (Trabalho original publicado em 1954).

Winnicott, D. W. (2008). Da dependência à independência no desenvolvimento do indivíduo. Porto Alegre, RS: Artmed. (Trabalho original publicado em 1963).

\section{CONFLITOS DE INTERESSES}

Não há conflitos de interesses.

\section{FINANCIAMENTO}

Coordenação de Aperfeiçoamento de Pessoal de Nível Superior (CAPES).

\section{SOBRE OS AUTORES}

Guilherme de Andrade Salgado é mestre em Psicologia Clínica pela Pontifícia Universidade Católica do Rio de Janeiro. Atualmente é doutorando em Psicologia Clínica pela Pontifícia Universidade Católica do Rio de Janeiro.

e-mail: gui.a.salgado@gmail.com 
https://orcid.org/0000-0003-0282-6191

Carlos Augusto Peixoto Junior é mestre em Teoria Psicanalítica pela Universidade Federal do Rio de Janeiro e doutor em Saúde Coletiva pela Universidade do Estado do Rio de Janeiro. Atualmente é Professor do Departamento de Psicologia e do Programa de Pós-graduação em Psicologia Clínica da Pontifícia Universidade Católica do Rio de Janeiro.

e-mail: cpeixotojr@terra.com.br

https://orcid.org/0000-0002-8631-7409 